\title{
Effect of Aqueous Extract of Blackberry Nightshade (Solanum nigrum) Leaf on Carbonated Alcoholic Herbal Beverage (CAHB)-Induced Cerebellar Damage and Behavioural Changes in Adult Wistar Rats
}

\section{${ }^{1}$ EZE, GI; ${ }^{1}$ EKECHI, CO; ${ }^{* 2}$ EKUNDINA, VO; ${ }^{1}$ AKONOAFUA, KA}

\author{
${ }^{I}$ Department of Anatomy, University of Benin, Benin City, Nigeria \\ ${ }^{2}$ Department of Medical Laboratory Science, Afe Babalola University, Ado-Ekiti, Ekiti State, Nigeria. *Corresponding author Email: \\ kemvic30@gmail.com; other Emails: ekechichinyereogwo@gmail.com; kevinakonoafua@gmail.com; justjerryelisa@yahoo.com
}

\begin{abstract}
This study was aimed at investigating the effect of aqueous extract of Solanum nigrum leaf on carbonated alcoholic herbal beverage-induced cerebellar damage and behavioural changes. Thirty (30) adult Wistar rats weighing between $150 \mathrm{~g}$ and $220 \mathrm{~g}$ were allotted into 5 groups of 6 rats each. Animals in group A (control) were placed on normal diet for 56 days. Group B were further subdivided into B1 and B2. Group B1 received $9.4 \mathrm{ml} / \mathrm{kg}$ of CAHB for 42days, Group B2 received $9.4 \mathrm{ml} / \mathrm{kg}$ of CAHB for 42 days and were left to recover for the next 14 days. Group C received $400 \mathrm{ml} / \mathrm{kg}$ (high dose) of $S$. nigrum only for 56 days. Group D received $9.4 \mathrm{ml} / \mathrm{kg}$ of CAHB for 42 days and $200 \mathrm{~m} / \mathrm{kg}$ of $S$. nigrum for the next 14 days. Group E received $9.4 \mathrm{ml} / \mathrm{kg}$ of CAHB for 42 days and $400 \mathrm{mg} / \mathrm{kg}$ of $S$. nigrum for the next 14 days. The result showed that oral administration of CAHB at a dose of $9.4 \mathrm{ml} / \mathrm{kg}$ body weight daily for 42 days when given to rats, and when they were left to recover for 14 days significantly induced: cerebellar oedema, degeneration of Purkinje cells, vascular stenosis and ulceration, as revealed by reduction in the activity of locomotive, exploratory and anxiety levels of the rats using open field locomotor test. Groups treated with the extract revealed normal cerebellar microstructure. This study has shown that the aqueous extract of S. nigrum leaf has an ameliorative effect on CAHB induced cerebellar damage and behavioural changes.
\end{abstract}

\section{DOI: https://dx.doi.org/10.4314/jasem.v22i11.15}

Copyright: Copyright (C) 2018 Eze et al. This is an open access article distributed under the Creative Commons Attribution License (CCL), which permits unrestricted use, distribution, and reproduction in any medium, provided the original work is properly cited.

Dates: Received: 19 October 2018; Revised: 26 November 2018; Accepted 29 November 2018

Keywords: CAHB, Behavioural, Cerebellum, Wistar Rats

The toxic effects of alcohol are diverse. Worldwide, alcohol abuse is recognized as a major cause of mortality and morbidity, with significant health and economic consequences (Abubakar, Tillmann and Banerjee, 2015). Among Nigerian youths, herbal alcoholic drinks has been reported to be the most abused substance (Makinde, 2014). These herbal alcoholic drinks are consumed more than their counterparts by both male and female folks. They are also consumed by young and elderly ones because it is believed by the consumers that they contain body purifiers, antimalarial components and ingredients that strengthen the virility of men (Badmus, 2014). Alcohol-related cerebellar degeneration is one of the commonest causes of acquired cerebellar ataxia (Torink and Torp, 1986). Some schools of thought argue that the direct toxic effect of alcohol on cerebellar cells is responsible while others report that the nutritional factors particularly thiamine deficiency are required to drive the underlying process (Suzanne and Kril, 2014). The degree of ataxia was reported not to be associated with the total life time consumption of alcohol. However, degree of eye-foot incoordination was related to increasing alcohol consumption when ataxic alcoholics and healthy control subjects were compared (Estrin, 1987). Nature has provided a complete store house of remedies to cure all ailment of mankind. These remedies are in form of herbs, plants and algae without having any toxic effect (Trees and Evans, 1983), thus, one of such plant is Solanum nigrum. Solanum nigrum is a medicinal plant, member of the solanecea family of plants. This family comprises many genera well known for their therapeutic properties. Solanum nigrum is commonly known as black night shade, which usually grows as a weed in moist habitats, different kinds of soils including dry, stony, shallow or deep soils. It can also be used for reclaiming degraded land (Kiran et al., 2009). Solanum nigrum possess components that are responsible for diverse activities. The major active components are glycoalkaloids, glycoproteins and polysaccharides. It also contains polyphenoic compounds such as gallicacid, cathechin, protocatechuic acid (PCA), caffeic acid, epicatechin, rutin and naringerim (Sikdar and Duttau, 2008). It is also used in oriental system of medicine for various purposes such as, anti-tumorigenic and anti-oxidant (Lee and Lim, 2003), anti-inflammatory, diuretic and antipyretic agent (Zakaria et al., 2006) and hepatoprotective (Rajul et al., 2003). The leaves stem and roots are used as a poultice or wash to treat cancerous sores, leucoderma and wounds while extracts of the plants are claimed to possess antispasmodic and vasodilatory effects (Ong, 2003). The present study was, therefore, designed, to evaluate the effect of aqueous leaf extract of Solanum nigrum 
on the interaction of carbonated alcoholic herbal beverage and rats' cerebellum.

\section{MATERIALS AND METHOD}

Plant material: Leaves of Solanum nigrum were obtained from Okhoro village, Egor local government area of Edo state, Nigeria. The plant was identified and authenticated by its fruits and leaves from the Plant Biology and Biotechnology Department in University of Benin. The leaves of Solanum nigrum were air dried for two weeks and pulverized into fine thin powder using mechanical grinder and stored in a covered plastic container, out of which $280 \mathrm{~g}$ was weighed and soaked in 14 litres of distilled water in a plastic bowl that was not covered. This mixture was stirred constantly for 3 days (72 hours) with the temperature kept at room temperature. The mixture was first filtered using a filter paper and conical flask and the solid residue removed. The filtrate was then re-filtered by passing it through cotton wool placed in Buchnner funnel severally. The final filtrate was concentrated using a rotary evaporator and water bath over a temperature of $45^{\circ} \mathrm{c}$ and freeze dried. The solid residue left over after freeze drying was weighed, stored in a plain plastic bottle and kept in the refrigerator throughout the administration period.

Experimental animals: Thirty (30) adult Wistar Rats weighing 150 - 220g were procured from the animal house of the Department of Anatomy, School of Basic Medical Sciences, College of Medical Sciences, University of Benin, Benin-City, Edo state, Nigeria. The animals were housed in the Animal facility of the same department and kept in a standard wooden cage that is well ventilated, under a conducive temperature with a 12:12 light and dark cycle. The animals were fed with standard growers' marsh and water ad libitum and cages were cleaned every day. The animals were acclimatized for a period of fourteen (14) days. Animal handling was performed according to Good Laboratory Practice (GLP). All animal experiments were done in accordance with the National Research Council, Guide for care and Use of Laboratory Animal. The experimental animals were grouped into five groups: A, B, C, D and E, of six rats each. Group $\mathrm{B}$ was further divided into subgroups B1 and B2. The experiment lasted for a period of fifty-six (56) days. The Wistar rats were provided with food and water $a d$ libitum. Group A: Animals served as control group, were administered $1 \mathrm{ml}$ of distilled water and fed for 56 days. Group B1: Animals were administered with $9.4 \mathrm{ml} / \mathrm{kg}$ of carbonated herbal alcohol drink only for 42 days. Group B2: Animals were administered with $9.4 \mathrm{ml} / \mathrm{kg}$ of carbonated herbal alcohol drink only for 42 days, then left for the next 14 days to recover without administering the carbonated alcoholic herbal drink. Group C: Animals were administered with $400 \mathrm{mg} / \mathrm{kg}$ of aqueous leaf extract of Solanum nigrum only for 56 days. Group D: Animals were administered with $9.4 \mathrm{ml} / \mathrm{kg}$ of carbonated herbal alcohol for 42 days and then administered $200 \mathrm{mg} / \mathrm{kg}$ of aqueous leaf extract of Solanum nigrum for the next 14 days. Group E: Animals were administered with $9.4 \mathrm{ml} / \mathrm{kg}$ of carbonated herbal alcohol for 42 days, then given $400 \mathrm{mg} / \mathrm{kg}$ of aqueous leave extract of Solanum nigrum for the next 14 days.

Animal behavioral study: The open field test was used to assess the animals' general locomotor activity and anxiety level as described by Brown, et al., (1999). These assessments were carried out after the administration (posttest). The images were captured and analyzed.

Procedures for sample collection: After 42 days of commencement of administration of CAHB, the rats in group B1 were re-weighed to determine their final weight, then sacrificed via anesthesia method. The brain tissues were harvested, weighed and followed by prompt fixation. Gross examination was carried out to investigate any physical or morphological changes associated with the organs harvested. The same procedure was also used after 56 days of the administration of CAHB; the rats in groups A, B2, C, $\mathrm{D}$ and $\mathrm{E}$ were sacrificed as well. The harvested organs were placed in labeled universal bottles fixed for 48 hours. Thereafter the tissue was processed using automatic tissue processing schedule to minimize the introduction of artifacts according to Ekundina and Eze, (2015). After sacrificing the animals, the required organs were carefully harvested and fixed in $10 \%$ formal saline, thereafter, re-fixed in a Bouin's fluid. The tissues were dehydrated in alcohol, cleared in xylene and impregnated in paraffin wax, the tissue blocks were then sectioned using rotary microtome at 5 micron per thickness, dewaxed in xylene and rehydrated in descending order before staining with hematoxylin and eosin, then observed microscopically.

Statistical analysis: Body weight change, organ weight change and Open field locomotor parameters were evaluated for statistical significance. Data were analyzed by analysis of variance using the statistical package for the social sciences (SPSS), version 17.0 (SPSS, Inc., Chicago, Illinois, USA). The analyzed data were represented in bar charts. The level of significance was set at $\mathrm{P}<0.05$.

\section{RESULTS AND DISCUSSION}

The Histomorphology of sub group B1 \& B2 revealed that consumption of carbonated alcoholic herbal beverage showed degeneration/atrophy of Purkinje cells, cerebellar oedema, vascular stenosis and vascular ulceration. The results of this experiment suggest that the distortion of the Purkinje cells could have been associated with functional changes that may be detrimental to the health of the rats. Atrophy of Purkinje cells and the poor development of the surviving ones led to a decrease in inhibitory function 
of its fibres which consequently resulted in a decrease in motor coordination in the cerebellar cortex. (Sahraoui, et al., 2001). Chemically induced neurodegeneration is usually characterized by different patterns of neuronal cell death, gliosis, swollen or destroyed axons, or destruction of myelin sheath (Cavanagh, 1987). Neuronal degeneration has been reported to result in cell death, which is of two types namely apoptotic and necrotic cell death and these two types differ morphologically and biochemically (Wyllie, 1980). Pathological cell death is regarded as necrosis and could result from extrinsic insults to the cell such as osmotic, toxic and traumatic (Faber, et al., 1981). Cell death in response to toxins occurs as a controlled event involving a genetic programme in which caspase enzymes are activated (Waters, et al., 1994).

Patchy vascular intimal erosion/ulceration indicates atherosclerosis which is the most common vascular disease and is a major cause for stroke and vascular dementia (Hilton and Shivane, 2015). Cerebellar infarction may also result, which presents with symptoms such as unsteadiness of gait, dizziness, nausea and vomiting as early symptoms. (Harding, 1990; Harding, 1992; Dow, et al., 1991). Cerebellar Oedema and tissue oedema as revealed is excessive accumulation of fluid in the intracellular or extracellular spaces of the brain. This condition accompanied with cerebellar infarction can lead to sudden respiratory arrest due to increased intracranial pressure in the posterior fossa. (Harding, 1992; Dow et al., 1991). CAHB may have acted as toxins to neuronal cells, thereby, affecting their cellular integrity and causing defects in membrane permeability and cell volume and homeostasis.

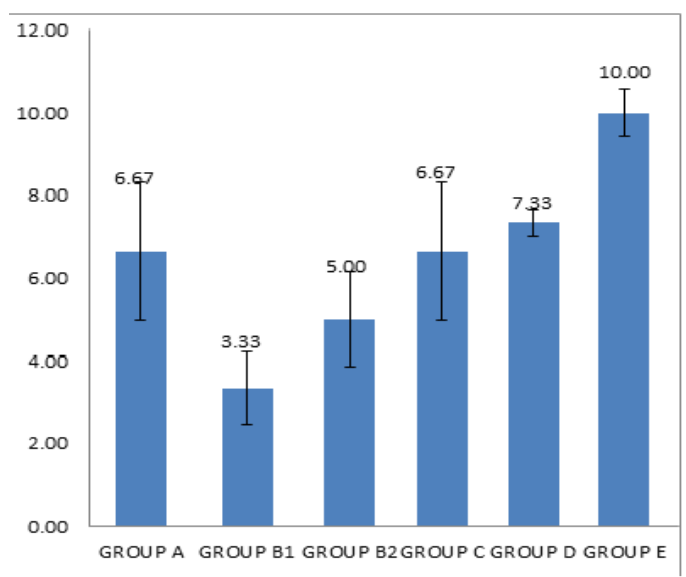

Fig 1: shows the frequency of rearing observed in different groups. The increase and decrease observed in the frequency of rearing of the experimental animals was not statistically significant $(\mathrm{P}>0.5)$ when compared to control. Whereas between the group given CAHB only ( group B1) and the groups given CAHB and S. nigrum (D \& E) the increase in rearing frequency were statistically significant $(\mathrm{P}<0.05)$.

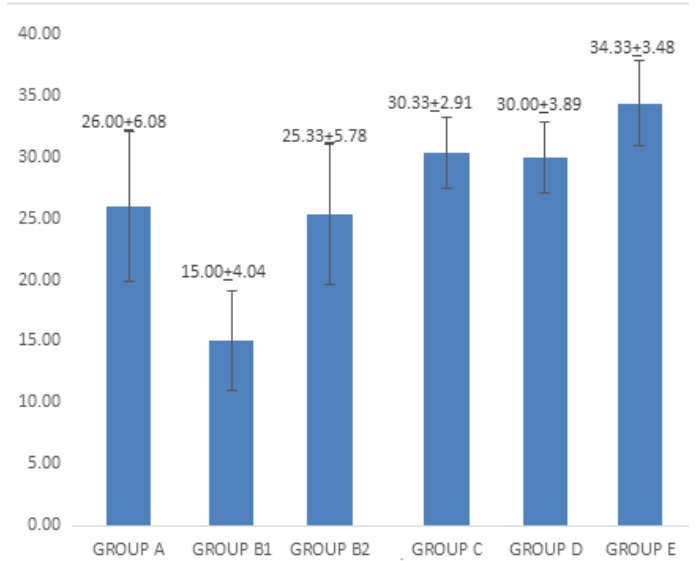

Fig 2: shows the frequency of line crossing observed in different groups. The increase and decrease observed in the frequency of line crossing of the experimental animals was not statistically significant $(\mathrm{P}>0.5)$ when compared to control. Whereas between the group given CAHB only ( group B1) and the groups given CAHB and $S$. nigrum (D \& E) the increase in rearing frequency were statistically significant $(\mathrm{P}<0.05)$.

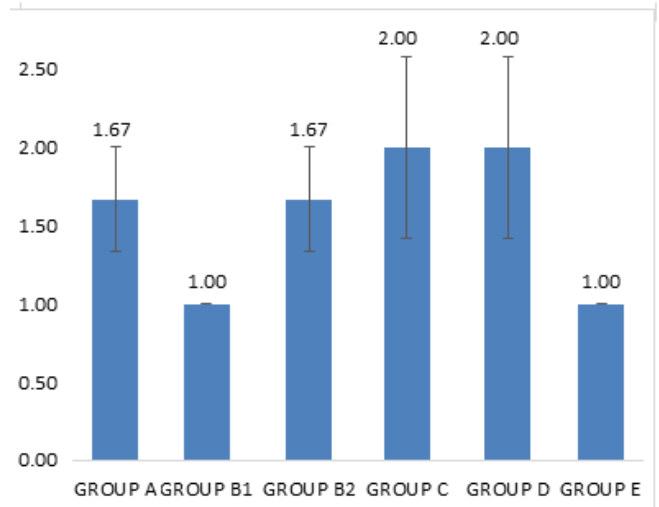

Fig 3: shows the number of fecal boli observed in different groups. The increase and decrease observed in the number of fecal boli of the experimental animals was not statistically significant $(\mathrm{P}>0.5)$ when compared to control and also among themselves.

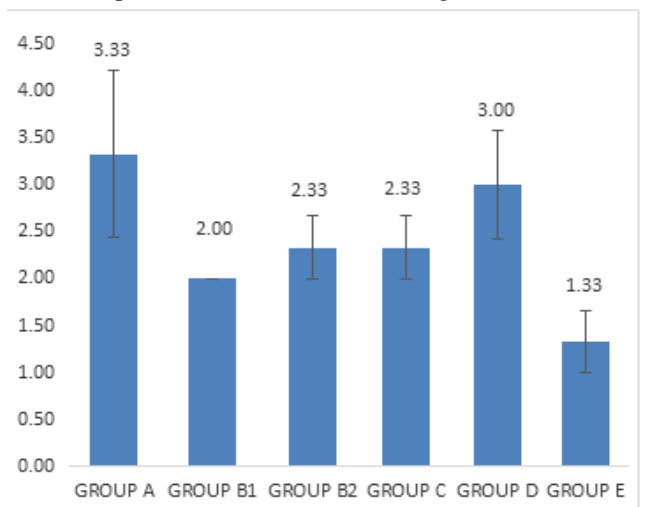

Fig 4: shows the frequency of grooming observed in different groups. The increase and decrease observed in the frequency of grooming of the experimental animals was not statistically significant $(\mathrm{P}>0.5)$ when compared to control except group $\mathrm{E}$ which was statistically significant $(\mathrm{P}<0.05)$. 


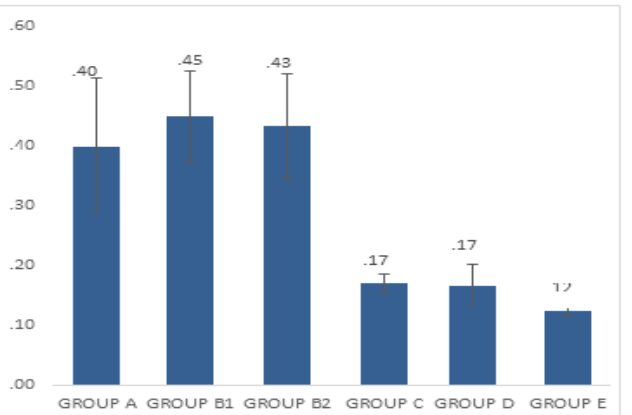

Fig 5: shows the amount of time spent closed to the wall or closed arm (Thigmotaxis). Group B and C were not statistically significant $(\mathrm{P}>0.05$ ) when compared to control group (group A) whereas Group D \& E were statistically significant $(\mathrm{P}<0.05)$.

The treated groups showed normal histoarchitecture of the cerebellum, thereby indicating that the plant extract Solanum nigrum showed a protective effect on the cerebellum of the Wistar rat. This is in agreement with the work carried out by Chinthana and Ananthi (2012) showing protective effect of an aqueous leaf extract of Solanum nigrum extract was examined against lead acetate Swiss albino mice. The oral administration of the extract for 30 days against lead acetate-affected mice significantly increased the levels of antioxidants (SOD, CAT, GPx) and decreased the level of lipid peroxidation (LPO).

Plate 1 shows photomicrographs of cerebellum in all the experimental groups. Microscopic findings showed that oral administration of CAHB at a dose of $9.4 \mathrm{ml} / \mathrm{kg}$ body weight per day for 42 days resulted in cerebellar oedema, vascular ulceration and degeneration of Purkinje cells. Severe vascular stenosis was also seen in the group that was given CAHB and left to recover for the next 14 days (plate $1 \mathrm{~b}$ and $1 \mathrm{c}$ ) when compared to the control group (1a). It was also found that at a dose of $200 \mathrm{mg} / \mathrm{kg}$ and $400 \mathrm{mg} / \mathrm{kg}$ of the $S$. nigrum extract, the cerebellum maintained its microstructure (plate d, e and f) when compared to control group.

The results of the present study, provide clear evidence of defence provided by $S$. nigrum extract against lead acetate-induced toxicity in the brain of albino mice. Evaluation of the antioxidant potential of Solanum nigrum leaves on the modulation of a $6 \mathrm{~h}$ restraintinduced oxidative stress, which suggests that Solanum nigrum was better as an antioxidant with post-restraint treatment than with pre-restraint administration (Zaidi et al., 2014). Work by Heaton et al (2004) showed that in the presence of exogenous antioxidant vitamin $\mathrm{E}$, neuronal survival level was enhanced in the developing cerebellum of the Wistar rat that were intoxicated with ethanol. Pycnogenol (a pated combination of bioflavonoids extracted from the bark of French maritime pine (Pinus maritima)) protected the developing cerebellar granular cell from ethanol neurotoxicity.

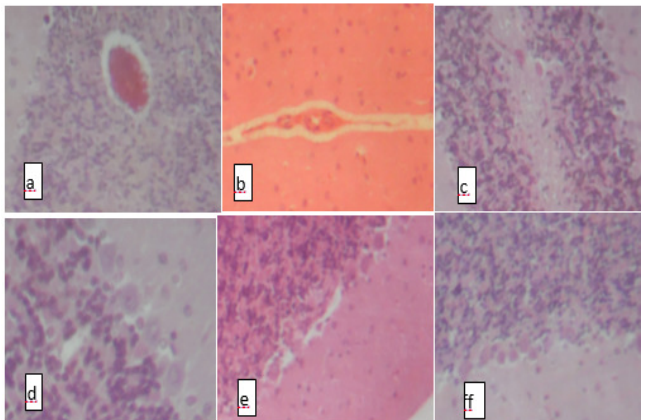

Plate 1 :(a): Control Rat cerebellum composed of : A, molecular layer B, Purkinje layer C, cerebellar vein and D, granular layer (H\&E X 40) (b) Rat cerebellum given 9.4ml CAHB for 42 days then left for the remaining 14 days of experiment showing: A,mild cerebellar oedema and B,severe vascular stenosis (H\&E X 40) (c) Rat cerebellum given $9.4 \mathrm{ml}$ carbonated alcoholic herbal beverage(CAHB) for 42 days then sacrificed showing: A,milld cerebellar oedema and B,mild Purkinje cell atrophy (H\&E X 40) (d) Rat cerebellum given $400 \mathrm{mg} / \mathrm{kg}$ S.nigrum only for 56 days showing: A,normal granular B,Purkinje and C,molecular layers (H\&E X 100) (e) Rat cerebellum given $9.4 \mathrm{ml} \mathrm{CABH}$ for 42 days then $200 \mathrm{mg} / \mathrm{kg}$ S.nigrum for 14 days showing : normal A, granular B,Purkinje and C, molecular layers (H\&E X 40) (f) Rat cerebellum given $9.4 \mathrm{ml}$ $\mathrm{CABH}$ for 42 days then $200 \mathrm{mg} / \mathrm{kg}$ S.nigrum for 14 days showing : normal A, granular B,Purkinje C, molecular layers (H\&E X 40).

The mechanism of action is by inhibiting apoptosis and necrosis of the developing neurons and oxidant scavenging and modulation of endogenous, cellular proteins (Silar-Marsiglio et al., 2005). Impaired antioxidant defense mechanism and oxidative stress are implicated in the pathogenesis of arsenic toxicity in the developing cerebellum. However, the administration of lipoic acid (which has been shown to have substantial antioxidant properties) overcame arsenic-induced deficits in the antioxidant enzyme activities and increase in oxidant production and lipid peroxidation level in the brain regions (Shila et al., 2005). The most important outcome in open field test is movement coordination, which is greatly influenced by motor output and exploratory drive (Ajibade et al., 2011). In this study, CAHB decreased line crossing and rearing which constitute exploratory behaviour. Direct deficits in open field exploratory behaviour following carbonated alcoholic herbal beverage administration manifested as a suppression of open field locomotor activity. The decreased locomotor activity of the treated animals compared with control, might be partly due to neurotoxic effect of alcohol on neuronal cells of the cerebellar cortex and the associated neurotransmitter substances. The neurotoxic effects of the carbonated alcoholic herbal beverage on the cerebellar cortex of these rats that were subjected to open field test and resulted in cerebellar cortical degeneration had already been reported in (Ajibade et al., 2006). The marked suppression of exploration and locomotion is probably a consequence of neuronal degeneration in the cerebellar cortex. This might have affected the integrity of the neuronal cells in the cerebellar cortex. Similarly, it shows degeneration and massive loss of Purkinje cells, which are the principal neurons in the 
cerebellum, following herbal quinine administration (Ajibade et al., 2008). Decrease in the parameters of line crossing and rearing are indicative of impaired motor functions and exploratory drive respectively in the experimental rat (Santiago et al., 2010 and brown et al 1999). Anxiety can be referred to as behavioral, physiological and psychological states induced in animals and humans by stress-resembling conditions. It is characterized by a feeling of fear or dread. Fear is a motivational state stimulated by specific stimuli that result in escape or defensive behaviors (Navqi et al., 2012). Rodents normally prefer to spend more time in the closed areas than open areas. Increase in time spent in open areas points to anti-anxiety (anxiolytic) behaviors. Thus exposures to aqueous extract of Solanum nigrum results in anxiogenic behaviors in Wistar rats. Considering that the cerebellum coordinates muscular activities of the body, it is possible that alteration to its microstructure may have resulted in the observed motor deficiencies during the open field tests.

\section{REFERENCES}

Abubakar, II; Tillmann, T; Banerjee, A (2015). "Global, regional, and national age-sex specific all-cause and cause-specific mortality for 240 causes of death, 1990-2013: a systematic analysis for the Global Burden of Disease Study 2013." Lancet 385: 9963 117-171.

Ajibade, AJ; Adenowo, T K; Fegemilehin, ME; Caxton-Martins, EA; Omotoso, EO (2006). Some histological observations on the cerebellar cortex of adult wistar rats following quinine administration. Sci. Focus 11 (2): 97-100

Allsop, J; Turner, B (1966). Cerebellar degeneration associated with chronic alcoholism." J. of the Neuro. Sci. 3 (3): 238-258.

An Lei, JT; Tang, X M; Liu-Gao, NN (2006). Review about mechanisms of anti-cancer of Solanum nigrum. Zhongguo Zhong yao za zhi= Zhongguo zhongyao zazhi= China J. of Chinese materia medica 31(15): 1225-6.

Badmus, Temidayo. Orijin: The Brand That Came, Saw and Conquere. www.nairaland.com/1862866/orijin-brand-camesaw-conquered (2014). Retrieved on October 17, 2018.

Brown, RE; Stephanie, C; Angela, K. (1999). Differences in measures of exploration and fear in MHC-congenic C57BL/6J and B6-H-2K mice." Behav. Gen. 29 (4) 263-271.

Chinthana, P; Ananthi, T (2012). J. of Chem. and Pharm. Res., 2(1): 72-74.
Dhellot, JR; Matouba, E; Maloumbi, MG; Nzikou, JM; Dzondo, MG; Linder, M; Parmentier, M; Desobry, S (2006). Extraction and nutritional properties of Solanum nigrum L seed oil." Afri. J. of Biotech. (5): 10-17

Ekundina, VO; Eze, G (2015). Common artifacts and remedies in histopathology (a review)." Afri. J. of Cell. Path. (4): 6-12.

Estrin, William J (1987). Alcoholic cerebellar degeneration is not a dose-dependent phenomenon. Alcoho: Clin. and Exp. Res. 11 (4): 372-375.

Eze, GI; Ekundina, VO Udeh, VC (2016). The effects of carbonated Alcoholic Herbal beverage on the cerebellum Histopathology and behavioral pattern in Adult Wistar Rats. BJMLS. (1): 30-36

Hadj-Sahraoui, N; Florence F; Hadi Z; Nicole, DB; Karl, H; Jean, M; (2001). Progressive atrophy of cerebellar Purkinje cell dendrites during aging of the heterozygous staggerer mouse (Rora+/sg). Develop. Bra. Res. 126, (2): 201-209.

Heaton, M B; Irina, M; Michael, P; Kendra, I; Siler, M (2004). Vitamin E amelioration of ethanol neurotoxicity involves modulation of apoptotisrelated protein levels in neonatal rat cerebellar granule cells. Develop. Bra. Res. 150 (2): 117124.

Jaatinen, P; Jyrki, R; (2008). Mechanisms of ethanolinduced degeneration in the developing, mature, and aging cerebellum. The Cerebellum 7 (3): 332-347.

Kiran, KR; Miti, R; Amit, P (2009). Reclaiming degraded land in India through the cultivation of medicinal plants." Bot. Res. Int. (2): 174-181.

Kumar, V; Prashanth, S; Shashidhara, M; Kumar M, Sridhara, BY (2001). Cytoprotective role of Solanum nigrum against gentamicin-induced kidney cell (Vero cells) damage in vitro." Fitoterapia 72 (5): 481-486.

Lee, SJ; Lim, KT (2003). Antioxidative Effects of Glycoprotein Isolated from Solanum nigrum Linne on Oxygen Radicals and its Cytotoxic Effects on the MCF-7 Cell." J. offood Sci. 68, (2): 466-470.

Li, Jian; Qing-Wang Li, Da-Wei G; Zeng, SH; WenZong L (2009). Antitumor and immunomodulating effects of polysaccharides isolated from Solanum nigrum Linne. Phyt. Res. 23 (11): 1524-1530. 
Li, J; Qingwang, L; Tao, F; Tao, Z; Kun, L; Rui, Z; Zengsheng, H; Dawei, G (2007). Antitumor activity of crude polysaccharides isolated from Solanum nigrum Linne on U14 cervical carcinoma bearing mice. Phytotherapy Research: An International Journal Devoted to Pharmacological and Toxicological Evaluation of Natural Product Derivatives 21 (9): 832-840.

Lim, Kye-Taek (2015). "Glycoprotein isolated from Solanum nigrum L. kills HT-29 cells through apoptosis." Journal of medicinal food 8 (2) 215 226.

Lin, HM; Hsien-Chun, T; Chau-Jong W; CharngCherng, C; Ko-Kaung, L; Pei-Ling; Fen-PC (2007). Induction of autophagy and apoptosis by the extract of Solanum nigrum Linn in HepG2 cells." J. of agricul. and food chem. 55 (9) 36203628.

Makinde, T. "Alcoholic aphrodisiac: Nigerian youths' new dangerous passion Published in Life \& Living Daily tribune newspaper" www.alcoholweekly.blogspot.com Food Chem., (2015) 55(9): 3620-3628.

Naqvi, F; Saida, H; Tahira, P; Darakhshan, JH (2012). Sub-chronic exposure to noise affects locomotor activity and produces anxiogenic and depressive like behavior in rats." Pharm. Rep. 64 (1) 64-69.

Ravi, V; Saleem, TSM; Patel, SS; Raamamurthy, J; Gauthaman, K (2009). Anti-inflammatory effect of methanolic extract of Solanum nigrum Linn berries. Inter. J. of Applied Res. in Nat. Prod. 2(2): 33-36.

Santiago, RM; Janaína, B; Marcelo, MS; Lima, PA; Dombrowski, RA; Maria,V (2010). Depressivelike behaviors alterations induced by intranigral MPTP, 6-OHDA, LPS and rotenone models of Parkinson's disease are predominantly associated with serotonin and dopamine. Prog. in NeuroPsychopharm. and Biol. Psychi. 34, (6)11041114.

Shila, SV; Kokilavani, V; Subathra, M; Panneerselvam, C (2005). Brain regional responses in antioxidant system to $\alpha$-lipoic acid in arsenic intoxicated rat. Toxicology 210 (1) 25-36.
Sikdar, M; Uzzal, D; (2008). Traditional phytotherapy among the Nath people of Assam. Studies on Ethno-Med. 2 (1): 39-45

Siler, M; Kendra, I; Qun, P; Michael, P; Irina, M; Nila, C; Khurana-Marieta, BH (2005). Mitochondrially targeted vitamin $\mathrm{E}$ and vitamin $\mathrm{E}$ mitigate ethanolmediated effects on cerebellar granule cell antioxidant defense systems. Bra. Res. 1052 (2): 202-211.

Sridhar, TM; Josthna, P; Naidu, CV (2011). Antifungal activity, phytochemical analysis of Solanum nigrum (L.)-an important antiulcer medicinal plant." J. of Ecobiotech.

Suzanne, M; Jillian, J: Kril, K (2014). Human alcoholrelated neuropathology." Acta neuropatho. 127, (1): 71-90.

Torvik, A; Sverre, T (1986). The prevalence of alcoholic cerebellar atrophy: a morphometric and histological study of an autopsy material." J. of the Neurolo.l Sci. 75 (1) 43-51.

Trease, GE; Evans, W C (1983).Text book of Pharmacognosy London." BailliareTindall 12, Pp 336.

Tull, Delena. Edible and useful plants of Texas and the southwest: a practical guide. University of Texas Press, 1999.

Walsh, N; Robert, AC (1976). The open-field test: a critical review." Psychological bulletin 83 (3): 482.

Wheaton, TA; Ivan, S (1965). Quantitative analysis of phenolic amines using ion-exchange chromatography. Anal. biochem. 12 (3): 585-592

Zakaria, Zainul Amiruddin, Hanan Kumar Gopalan, Hairani Zainal, Nur Hidayu Mohd Pojan, Nur Atiqah Morsid, Anwariah Aris, and Mohd Roslan Sulaiman. (2016) "Antinociceptive, antiinflammatory and antipyretic effects of Solanum nigrum chloroform extract in animal models." Yakugaku Zasshi 126 (11): 1171-1178.

Zhou, Xinlan, Xiangjiu He, Guanghui Wang, Hao Gao, Guangxiong Zhou, Wencai Ye, and Xinsheng Yao (2006). Steroidal saponins from Solanum nigrum." J. of Nat. products 69 (8): 1158-1163. 